\title{
Thermodynamic Study and Spectroscopic Analysis of a Charge-Transfer Complex between 3,5-Diamino-1,2,4-Triazole and 6-Methyl-1,3,5-Triazine-2,4-Diamine with Chloranilic Acid
}

\author{
Khairia M. Al-Ahmary*, Ashwaq T. Alharbi \\ University of Jeddah, College of Science, Department of Chemistry, Jeddah, Saudi Arabia \\ Email: *kmal-ahmary@uj.edu.sa
}

How to cite this paper: Al-Ahmary, K.M. and Alharbi, A.T. (2020) Thermodynamic Study and Spectroscopic Analysis of a ChargeTransfer Complex between 3,5-Diamino1,2,4-Triazole and 6-Methyl-1,3,5-Triazine2,4-Diamine with Chloranilic Acid. Open Journal of Physical Chemistry, 10, 33-47. https://doi.org/10.4236/ojpc.2020.101002

Received: December 30, 2019

Accepted: February 10, 2020

Published: February 13, 2020

Copyright $\odot 2020$ by author(s) and Scientific Research Publishing Inc. This work is licensed under the Creative Commons Attribution International License (CC BY 4.0).

http://creativecommons.org/licenses/by/4.0/

\begin{abstract}
Studying of charge-transfer $(C T)$ and proton transfer interactions is essential due to their important role in many biological field and industrial applications. The current work will add more information's about the nature of interaction between 3,5-diamino-1,2,4-triazole (DAT) and 6-methyl-1,3,5-triazine-2,4-diamine (MTDA) with 3,6-dichloro-2,5-dihydroxy-p-benzoquinone (chloranilic acid CLA) which was studied spectrophotometrically in Ethanol (EtOH) and Methanol $(\mathrm{MeOH})$ solvents at different temperatures. The molecular composition of the formed complexes was studied by applying continuous variation and spectrophotometric titration methods and found to be 1:1 charge transfer complex for both Complex (DAT:CLA) and (MTDA:CLA) which are produced. Minimum-Maximum absorbance's method has been applied to calculate the formation constant $K_{C T}$ and molecular extinction coefficient ( $\varepsilon$; they recorded high values confirming high stability of the produced complexes. Oscillator strength $(f)$, transition dipole moment $(\mu)$, ionization potential $\left(I_{P}\right)$ and dissociation energy $(W)$ of the formed $C T$-complexes were also determined and evaluated; they showed solvent dependency. It is concluded that the formation constant $\left(K_{C T}\right)$ of the complexes is found to depend on the nature of both electron acceptor and donors and on the polarity of solvents.
\end{abstract}

\section{Keywords}

3,5-Diamino-1,2,4-Triazole, 6-Methyl-1,3,5-Triazine-2,4-Diamine, Charge Transfer, Hydrogen Bond, Spectroscopy 


\section{Introduction}

Charge transfer $(C T)$ or proton transfer $(\mathrm{PT})$ complexation is one of the important operations which have many applications in many fields like a biological system such as DNA binding [1], antimicrobial activity, antibacterial, antifungal [2] and drug receptor [3]. Also, it used in controlling the speed of enzymatic reactions [4], modern technology like organic solar cells [5], electrical conductivity and optical properties [6].

Triazine compounds are well known due to their broad biological activity towards several diseases such as analgesic, anti-inflammatory, anti-oxidant, analeptic [7]. A great deal of attention has been paid to triazine derivatives endowed with antitumor activity [8], besides widely used in natural or synthetic, with a great variety of pharmacological effects [9].

Due to the importance of triazines in many fields and in continuation of our studies on charge or proton transfer, in this paper we would like to add some information's to the chemistry of triazanes through synthesis and characterization of a novel charge transfer complex including proton transfer hydrogen bonding between 3,5-diamino-1,2,4-triazole (DAT) as an electron donor is compared on their other electron donor 6-Methyl-1,3,5-triazine-2,4-diamine (MTDA) with electron acceptor chloranilic acid (CLA). This work presents the spectroscopic characterization of the charge transfer.

This work aims to compare between DAT and MTDA with CLA. The molecular composition of the formed complex will be identified through job's method of continuous variations and spectrophotometric titration methods. The formation constant (KCT) and molecular extinction coefficient $(\varepsilon)$ and spectroscopic physical parameters were estimated and evaluated including oscillator strength $(f)$, transition dipole moment $(m)$, ionization potential (ID), and resonance energy $\left(R_{N}\right)$ which were also calculated and analyzed. The bonding nature will be discussed through calculating thermodynamic parameters using Van't Hoff equation.

\section{Experimental}

\subsection{Materials, Stock Solutions and Instrumentation}

Powdered DAT (purity 98\%) was obtained from Across Organics, Powdered MTDA (purity 98\%) was supplied by Alfa Aesar (Germany).; chloranilic acid (purity 98\%) was obtained from Sigma Aldrich, and spectroscopic grade, ethanol and methanol were used without further purification. Standard stock solutions of DAT $\left(5 \times 10^{-3} \mathrm{~mol} \cdot \mathrm{L}^{-1}\right)$, MTDA $\left(5 \times 10^{-3} \mathrm{~mol} \cdot \mathrm{L}^{-1}\right)$ and CLA $\left(5 \times 10^{-3} \mathrm{~mol} \cdot \mathrm{L}^{-1}\right)$ were immediately prepared before each series of measurements by dissolving appropriate amount in $50 \mathrm{~mL}$ of solvent. All solutions were stored in dark place for at least one week.

\subsection{Instrumentation and Physical Measurements}

The electronic absorption spectra were recorded in the region $200-700 \mathrm{~nm}$ us- 
ing double beams ultra-violate visible spectrophotometer (Shimadzu UV-1601, Japan) with matched 1-cm quartz cells and personal spectroscopy software version 3.7, connected to Shimadzu TCC-ZUOA temperature controller unit (Japan).

\section{Results and Discussion}

\subsection{Observation of the $C T$ Band}

Figure 1 shows the electronic absorption spectra of the charge transfer complex 3,5-diamino-1,2,4-triazole (DAT) and 6-methyl-1,3,5-triazine-2,4-diamine (MTDA), with the e-acceptor chloranilic acid (CLA) and a mixture of both $5 \times 10^{-4} \mathrm{~mol} \cdot \mathrm{L}^{-1}$ $\mathrm{DAT}+5 \times 10^{-4} \mathrm{~mol} \cdot \mathrm{L}^{-1} \mathrm{CLA}$ and $5 \times 10^{-4} \mathrm{~mol} \cdot \mathrm{L}^{-1} \mathrm{MTDA}+5 \times 10^{-4} \mathrm{~mol} \cdot \mathrm{L}^{-1} \mathrm{CLA}$ in ethanol $(\mathrm{EtOH})$ and methanol $(\mathrm{MeOH})$ solutions. It is worth mentioning that, the mixing of the donor and acceptor gave immediate deep purple color in both Complex (DAT:CLA) and Complex (MTDA:CLA), which is evident for the formation of charge transfer complex and stable for two hours. A newly absorption band at $\lambda_{\max } 524.5 \mathrm{~nm}$ both in ethanol and methanol in Complex (DAT:CLA) detected that was attributed to the formation of the PT complex between DAT and CLA. While the $\lambda_{\max }$ in Complex (MTDA:CLA) is $524.5 \mathrm{~nm}$ and $524 \mathrm{~nm}$ in ethanol and methanol was attributed to the formation of the PT complex between MTDA and CLA. It is worth reporting, it used the blank included the same concentration of chloranilic acid to remove a possible overlap that may arise between complexes and acceptor absorption bands.

\subsection{Molecular Composition of the Formed HBCT Complex}

The molecular composition of the formed HBCT-complexes was determined by applying Job's method of continuous variations [10], The symmetrical curves with a maximum at 0.5 mole fraction indicating of 1:1 $C T$-complex formation in both (DAT:CLA) and (MTDA:CLA) in different solvents studied and a representative plot is given in (Figure 2).

In the Photometric titration method, small volumes of chloranilic acid are added to known concentration of donor and the absorption values are recorded against the added volume of CLA, where two straight lines were produced intercepting at 1:1 ratio of both (DAT:CLA) and (MTDA:CLA). Accordingly, one can conclude from Figure 2 and Figure 3 the solvent polarity has not any effect on the complex composition.

\subsection{Formation Constant of the Formed Complex}

Based on the electronic spectra of the HBCTI-complex at various donor's concentrations (Figure 4), $K_{\mathrm{F}}$ and $\varepsilon$ were calculated using the Minimum-Maximum absorbances method [11].

$$
K_{C T}=\frac{A_{\text {complex }}-A_{\text {min }}}{C_{\text {Donor }}\left(A_{\text {max }}-A_{\text {complex }}\right)}
$$



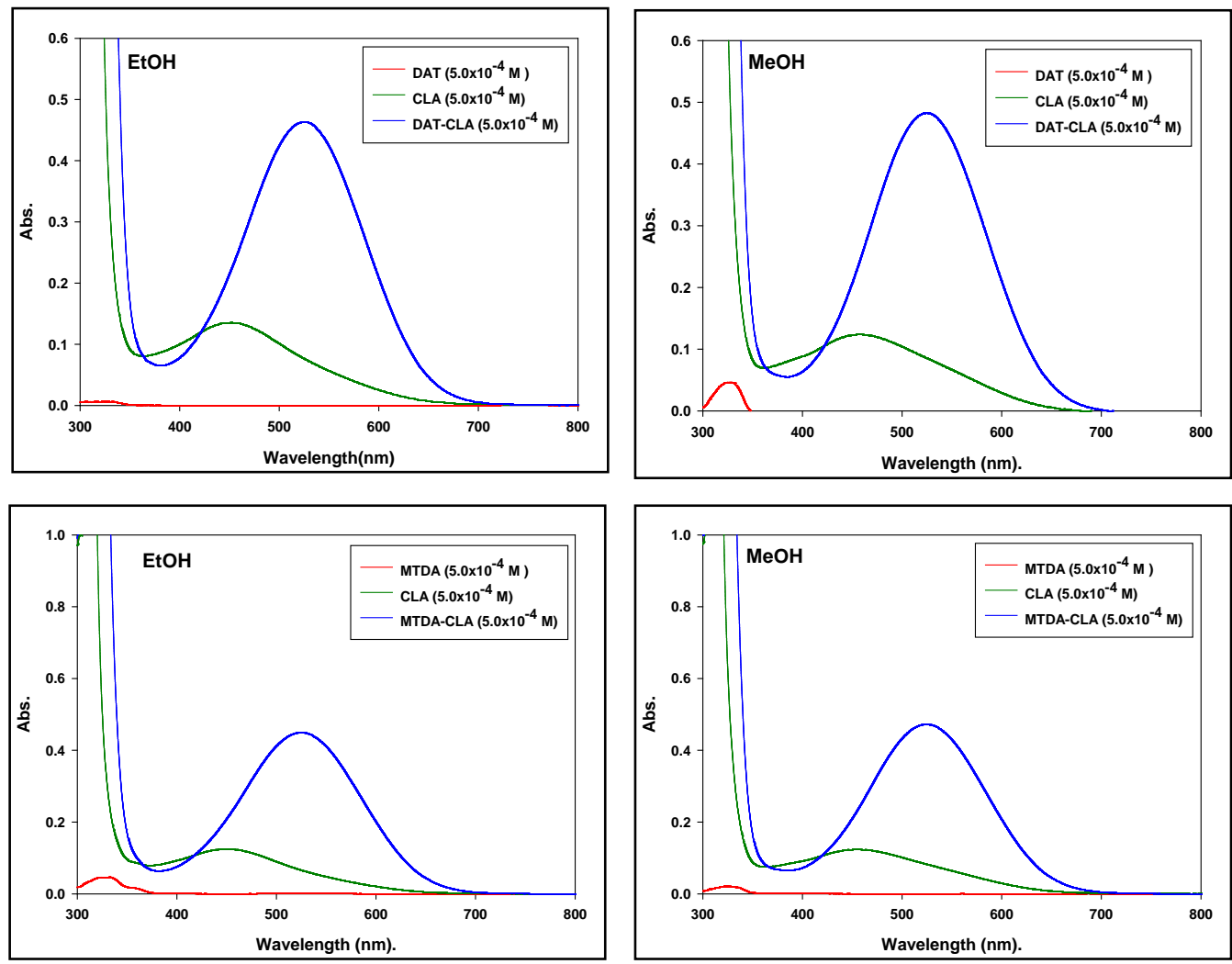

Figure 1. Electronic spectra of donor, acceptor and $C T$-complex in $\mathrm{EtOH}$ and $\mathrm{MeOH}$.
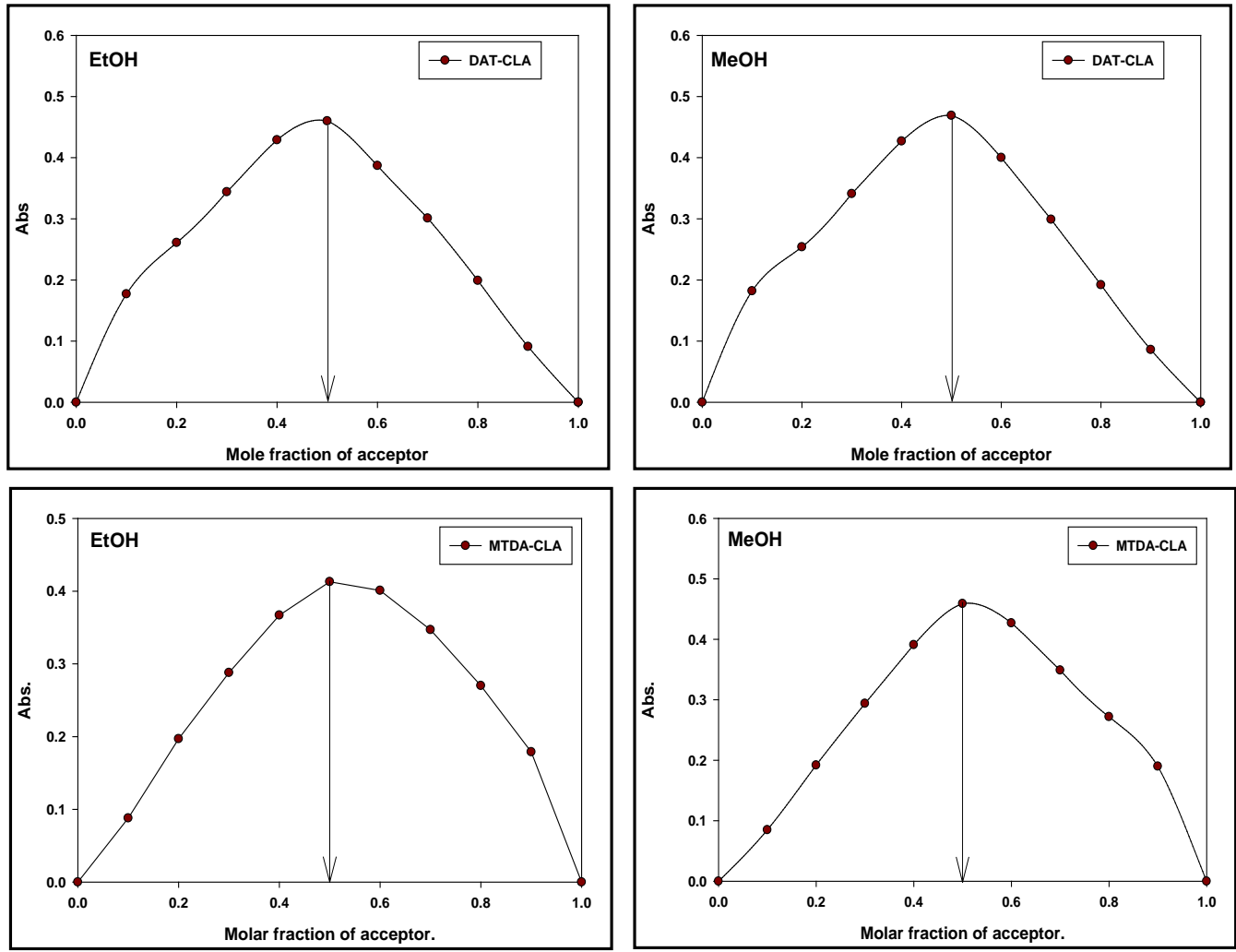

Figure 2. Job's plot of HBCTI-complexes in $\mathrm{EtOH}$ and $\mathrm{MeOH}$. 

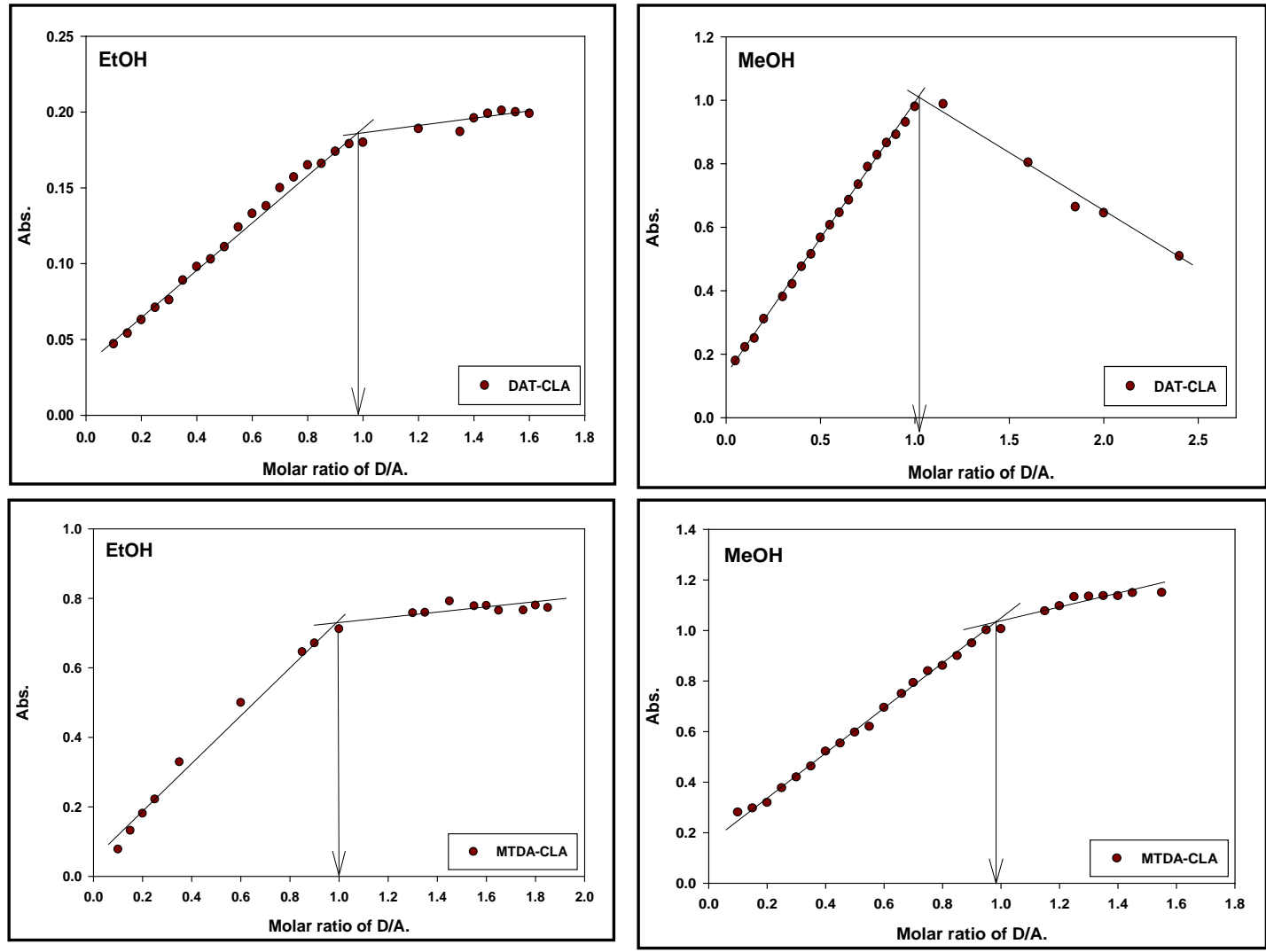

Figure 3. Photometric titration plot of $\mathrm{HBCTI}$-complexes in $\mathrm{EtOH}$ and $\mathrm{MeOH}$.
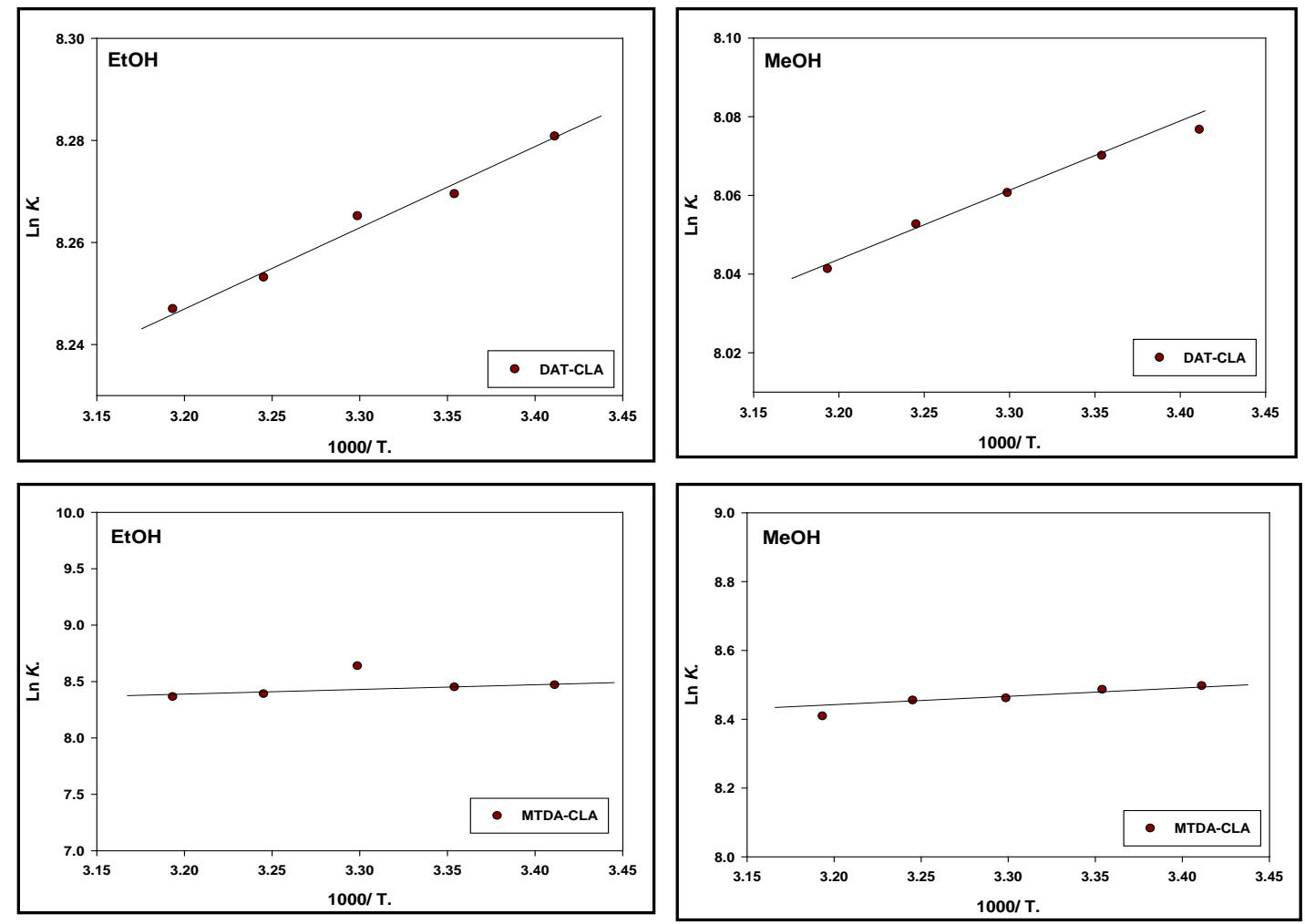

Figure 4. Van't Hoff plot of HBCTI-complexes in EtOH and $\mathrm{MeOH}$. 
where $A_{\max }$ is the maximum absorbance of the complex, $A_{\min }$ is the minimum absorbance of the complex, $A_{\text {complex }}$ is the complexes absorbance values between $A_{\max }$ and $A_{\min }$, and $C_{\text {Donor }}$ is the concentration of the added donor in mol. $\mathrm{L}^{-1}$. The set of equilibrium constants were averaged.

Can conclude from Table 1, there is a small variation in the formation constant between ethanol and methanol. The stability constant $\left(K_{C T}\right)$ of the formed complex DAT-CLA found equal to $3.9030 \times 10^{3} \mathrm{~L} \cdot \mathrm{mol}^{-1}$ and $3.1975 \times 10^{3} \mathrm{~L} \cdot \mathrm{mol}^{-1}$ in $\mathrm{EtOH}$ and $\mathrm{MeOH}$ respectively. On the other hand, the stability constant $\left(K_{C T}\right)$ of the formed complex MTDA-CLA found equal to $5.444 \times 10^{3} \mathrm{~L} \cdot \mathrm{mol}^{-1}$ and $4.846 \times 10^{3} \mathrm{~L} \cdot \mathrm{mol}^{-1}$ in $\mathrm{EtOH}$ and $\mathrm{MeOH}$ respectively.

From the above we conclude the Formation constant of MTDA-CLA is higher amounts and the higher stability of the complex DAT-CLA.

Where it seems that the stability of the formed complex is connected by solvent polarity where the higher polar solvent methanol exhibited the smaller value of the formation constant than ethanol. Consequently, the trend of increasing the formation constants follows the order $\mathrm{EtOH}>\mathrm{MeOH}$, as can be seen from Table 1.

The high values of the stability constant are attributed to the high donating power of donor, the high electron affinity of CLA and the high electric permittivity for both ethanol and methanol. On the other hand, the increase of electron density on the complex nitrogen facilitates the formation of proton transfer hydrogen bonding between the $\mathrm{H}$-donor Complexes $(\mathrm{OH})$ and the $\mathrm{H}$-acceptor of donors (ring nitrogen). This hydrogen bonding adds extra stability to the formed complex.

\subsection{Determination of the Spectroscopic Physical Data}

The stability of the formed complex can be evident from calculating the spectroscopic physical parameters These parameters included oscillator strength $(f)$, transition dipole moment $(\mu)$ [12], charge transfer energy $\left(E_{C T}\right)$ [13], ionization potential $\left(I_{P}\right)[14]$ and resonance energy $\left(R_{N}\right)$ [15].

The experimental oscillator strength $(f)$, which is a dimensionless quantity, used to express the transition probability of the CT-band [16] and transition dipole moment $(\mu)$ is a valuable tool that confirms the existence of proton transfer interaction in the formed complex, calculated through the following equations [17]:

$$
\begin{gathered}
f=4.32 \times 10^{-9}\left[\varepsilon_{\max } \cdot \Delta v_{1 / 2}\right] \\
\mu=0.0958\left[\varepsilon_{\max } \cdot \Delta v_{1 / 2} / \bar{\nu}_{\max }\right]^{1 / 2}
\end{gathered}
$$

where $\Delta v_{1 / 2}$ is the half bandwidth of absorbance, $\varepsilon_{\max }$ and $\bar{\nu}_{\max }$ are the molar extinction coefficient and wave number at the maximum absorption of the complex, respectively.

The charge transfer $E_{C T}$ energy is a measure of the ease of charge transfer from donor to the acceptor and it represents the transitions $\pi-\pi^{*}$ and $n-\pi^{*}$. 
Table 1. Spectroscopic physical data for HBCTI-complexes.

\begin{tabular}{|c|c|c|c|c|c|c|c|c|c|}
\hline Solvent & $\lambda_{\max }$ & $C_{\mathrm{CLA}}$ & $C_{\mathrm{DAT}}$ & $A_{\min }$ & $A_{\max }$ & $A_{\text {complex }}$ & $\begin{array}{l}K_{C T} \times 10^{-3} \\
\left(\mathrm{~L} \cdot \mathrm{mol}^{-1}\right)\end{array}$ & $\begin{array}{c}\text { Average } K_{C T} \times 10^{-3} \\
\left(\mathrm{~L} \cdot \mathrm{mol}^{-1}\right)\end{array}$ & $\varepsilon$ \\
\hline \multirow{8}{*}{$\begin{array}{l}\text { DAT-CLA } \\
\text { EtOH }\end{array}$} & \multirow{8}{*}{524.5} & \multirow{8}{*}{0.001} & 0.0002 & \multirow{8}{*}{0.075} & \multirow{8}{*}{0.713} & 0.169 & 0.8640 & \multirow{8}{*}{3.9030} & \multirow{8}{*}{758} \\
\hline & & & 0.0003 & & & 0.261 & 1.3717 & & \\
\hline & & & 0.0004 & & & 0.307 & 1.4286 & & \\
\hline & & & 0.0005 & & & 0.434 & 2.5735 & & \\
\hline & & & 0.0006 & & & 0.502 & 3.3728 & & \\
\hline & & & 0.0007 & & & 0.526 & 3.4454 & & \\
\hline & & & 0.0008 & & & 0.617 & 7.0573 & & \\
\hline & & & 0.0009 & & & 0.655 & 11.1111 & & \\
\hline \multirow{9}{*}{$\begin{array}{l}\text { DAT-CLA } \\
\text { MeOH }\end{array}$} & \multirow{9}{*}{524.5} & \multirow{9}{*}{0.001} & 0.0002 & \multirow{9}{*}{0.073} & \multirow{9}{*}{0.815} & 0.140 & 0.4963 & \multirow{9}{*}{3.1975} & \multirow{9}{*}{558} \\
\hline & & & 0.0003 & & & 0.232 & 0.9091 & & \\
\hline & & & 0.0004 & & & 0.297 & 1.0811 & & \\
\hline & & & 0.0005 & & & 0.385 & 1.4512 & & \\
\hline & & & 0.0006 & & & 0.513 & 2.4283 & & \\
\hline & & & 0.0007 & & & 0.548 & 2.5415 & & \\
\hline & & & 0.0008 & & & 0.636 & 3.9316 & & \\
\hline & & & 0.0009 & & & 0.702 & 6.1849 & & \\
\hline & & & 0.0010 & & & 0.746 & 9.7536 & & \\
\hline \multirow{10}{*}{$\begin{array}{l}\text { MTDA-CLA } \\
\text { EtOH }\end{array}$} & \multirow{10}{*}{524.5} & \multirow{10}{*}{0.001} & 0.0002 & & & 0.172 & 0.542 & \multirow{10}{*}{5.444} & \multirow{10}{*}{775} \\
\hline & & & 0.0003 & & & 0.264 & 1.185 & & \\
\hline & & & 0.0004 & & & 0.344 & 1.525 & & \\
\hline & & & 0.0005 & & & 0.422 & 1.942 & & \\
\hline & & & 0.0006 & $0 \cap 084$ & 0775 & 0.513 & 2.782 & & \\
\hline & & & 0.0007 & 0.001 & (1) & 0.559 & 3.215 & & \\
\hline & & & 0.0008 & & & 0.609 & 4.076 & & \\
\hline & & & 0.0009 & & & 0.676 & 6.997 & & \\
\hline & & & 0.0010 & & & 0.712 & 10.827 & & \\
\hline & & & 0.0012 & & & 0.744 & 21.153 & & \\
\hline \multirow{10}{*}{$\begin{array}{c}\text { MTDA-CLA } \\
\text { MeOH }\end{array}$} & \multirow{10}{*}{524} & \multirow{10}{*}{0.001} & 0.0002 & \multirow{10}{*}{0.068} & & 0.155 & 0.584 & \multirow{10}{*}{4.846} & \multirow{10}{*}{899} \\
\hline & & & 0.0003 & & & 0.252 & 0.947 & & \\
\hline & & & 0.0004 & & & 0.339 & 1.209 & & \\
\hline & & & 0.0005 & & & 0.414 & 1.426 & & \\
\hline & & & 0.0006 & & 080 & 0.503 & 1.830 & & \\
\hline & & & 0.0007 & & S & 0.563 & 2.104 & & \\
\hline & & & 0.0008 & & & 0.653 & 2.972 & & \\
\hline & & & 0.0009 & & & 0.752 & 5.170 & & \\
\hline & & & 0.0010 & & & 0.787 & 6.419 & & \\
\hline & & & 0.0012 & & & 0.873 & 25.80 & & \\
\hline
\end{tabular}


The charge transfer energy is calculated based on Equation (4) [13]

$$
E_{C T}=1243.667 / \lambda_{C T}
$$

The ionization potential $I_{D}$ is the energy required to remove an electron from the donor's molecular orbital participating in charge transfer interaction and can be calculated from Aloisi and Piganator equation.

$$
I_{D}(\mathrm{eV})=5.76+1.53 \times 10^{-4} \cdot v_{C T}
$$

The dissociation energy $(W)$ of the formed $C T$ complex was calculated from the corresponding $C T$ energy $\left(E_{C T}\right)$, the ionization potential of the donor $\left(I_{D}\right)$ and electron affinity of the acceptor $\left(E_{A}\right)$ using the following relationship [18]:

$$
E_{C T}=I_{P}-E_{A}-W
$$

The resonance energy $\left(R_{N}\right)$ is a ground state property that contributes to the stability of the formed complex. These parameters can be calculated using Equations (2)-(6).

$$
\varepsilon_{C T}=7.7 \times 10^{4} /\left[h v_{C T} /\left[R_{N}\right]-3.5\right]
$$

The calculated values of the different spectroscopic physical parameters in both Complex (DAT:CLA) and (MTDA:CLA) are reported in Table 2. As can be seen from Table 2 , the values of the oscillator strengths are increased gradually on moving from methanol to ethanol, confirming the high probability of charge transfer with less polar solvent ethanol in consisting with the stability constant values. On the other hand, the transition dipole moment follows the same trend as the oscillator strength of methanol was smaller than ethanol. Hence one concludes from Table 2, the probability of $H$-transfer in ethanol is higher compared with methanol. Furthermore, one can deduct from oscillator strength and transition dipole moment, that the stability of the formed complex is attributed to the presence of two interactions, the $C T$ (charge transfer) and PT proton transfer).

In Complex (DAT:CLA), the ionization potential recorded the same and small values in both $\mathrm{EtOH}$ and $\mathrm{MeOH}$, asserting the formation of stable complex and one can conclude that the same donor molecular orbital interacts with CLA to produce the charge transfer complex. The obtained ionization potential values recorded small values due to the high basicity of DAT (two nitrogen ring and two amino groups). While The ionization potential in Complex (MTDA:CLA) was recorded the same and little higher value than Complex (MTDA:CLA) in

Table 2. Spectroscopic physical parameters of complexes in different solvents.

\begin{tabular}{cccccccc}
\hline Complex & Solvent & $E_{C T}(\mathrm{eV})$ & $I_{P}(\mathrm{eV})$ & $W(\mathrm{eV})$ & $R_{N}$ & $f$ & $\mu(\mathrm{Debye})$ \\
\hline $\begin{array}{c}\text { Complex } \\
\text { (DAT:CLA) }\end{array}$ & $\mathrm{EtOH}$ & 2.3711 & 8.6771 & 5.2059 & 0.0226 & 0.4826 & 7.3329 \\
\hline $\begin{array}{c}\text { Complex } \\
\text { (MTDA:CLA) }\end{array}$ & $\mathrm{MeOH}$ & 2.3711 & 8.6771 & 5.2059 & 0.0168 & 0.3375 & 6.1322 \\
\hline
\end{tabular}


both $\mathrm{EtOH}$ and $\mathrm{MeOH}$ respectively, due to the high basicity of MTDA (three nitrogen ring, two amino groups and one methyl group).

This behavior suggests that the electron responsible for the basic strength of donors (n-electrons) is the same involved in the $C T$ interaction of donors with $\mathrm{CLA}$ in $\mathrm{EtOH}$ and $\mathrm{MeOH}$. Hence, the investigated donors behave as $\mathrm{n}$-donor towards $\pi$-acceptor (CLA). This means that the highest occupied molecular (HOMO) is the non-bonding molecular orbital and the $H$-bond complexing sites of donor is pyridinic like nitrogen by its lone electron pair. Therefore, the $C T$ interaction is attributed to the promotion of non-bonding electrons of the donors the lowest unoccupied $\pi$-molecular orbital of the acceptor CLA (LUMO). Consequently, one can deduce that the formed charge transfer complex is mainly $n-\pi$ type in both $\mathrm{EtOH}$ and $\mathrm{MeOH}$. It seems that the high donating power of donor from the presence of two ring nitrogen's and two amino in DTA and three nitrogen ring, two amino groups and one methyl group in MTDA groups is presumably responsible for this situation. The charge transfer energy recorded the same values in both $\mathrm{EtOH}$ and $\mathrm{MeOH}$.

\subsection{Determination of Thermodynamic Parameters}

The thermodynamic properties of the complexes were studied by estimating the enthalpy change, $\Delta H^{\circ}$ (k.J.mol $\left.{ }^{-1}\right)$, the entropy change, $\Delta S^{\circ}\left(\mathrm{J} \cdot \mathrm{k}^{-1} \cdot \mathrm{mol}^{-1}\right)$ and as well as Gibbs free energy change, $\Delta G^{\circ}\left(\mathrm{k} \cdot \mathrm{J} \cdot \mathrm{mol}^{-1}\right)$ of the charge transfer reaction. The $K_{C T}$ values for the [DAT-CLA] and [MTDA-CLA] systems at different temperatures were determined by minimum-maximum absorbances method. The thermodynamic parameters $\left(\Delta H^{\circ}, \Delta S^{\circ}\right)$ were calculated from the obtained $K_{C T}$ value at $20^{\circ} \mathrm{C}, 25^{\circ} \mathrm{C}, 30^{\circ} \mathrm{C}, 35^{\circ} \mathrm{C}$ and $40^{\circ} \mathrm{C}$ using the Van't Hoff equation:

$$
\ln K_{C T}=-\frac{\Delta H^{\circ}}{R T}+\frac{\Delta S^{\circ}}{R}
$$

where $\Delta H^{\circ}$ and $\Delta S^{\circ}$ are the enthalpy and entropy of the $C T$ complex formation, respectively. $R$ is the gas constant $\left(8.314 \mathrm{~J} \cdot \mathrm{mol}^{-1} \cdot \mathrm{k}^{-1}\right)$ and $T$ is the absolute temperature in Kelvin. Plotting the values of $\ln K_{C T}$ versus $1000 / T$, a straight line was obtained (Figure 4). The slope and intercept of the line were equal to $\left(-\Delta H^{\circ} / R\right)$ and $\left(\Delta S^{\circ} / R\right)$, respectively; thus, the values of $\Delta H^{\circ}$ and $\Delta S^{\circ}$ were determined.

The results obtained are given in Table 3 all complexes the value of formation constant decreases with increasing temperature in methanol and ethanol indicating that the $C T$ reaction is exothermic, where the enthalpy of formation $\left(-\Delta H^{\circ}\right)$ recorded 1.28 and $1.34 \mathrm{k} \cdot \mathrm{J} \cdot \mathrm{mol}^{-1}$ in $\mathrm{EtOH}$ and $\mathrm{MeOH}$, respectively in Complex (DAT:CLA) and in complex (MTDA:CLA) was recorded 4.65 and 3.15 $\mathrm{k} \cdot \mathrm{J} \cdot \mathrm{mol}^{-1}$ in $\mathrm{EtOH}$ and $\mathrm{MeOH}$, respectively. Consequently, the electron density increases on donors, leading to high $-\Delta H^{\circ}$.

One observes in Table 3, that the entropy $\Delta S^{\circ}$ recorded small different between $\mathrm{EtOH}$ and $\mathrm{MeOH}$ it was 64.5 and $62.6 \mathrm{~J} \cdot \mathrm{k} \cdot \mathrm{mol}^{-1}$ in Complex (DAT:CLA) while the entropy $\Delta S^{\circ}$ recorded small different between $\mathrm{EtOH}$ and $\mathrm{MeOH}$ it was 59.4 and $60.0 \mathrm{~J} \cdot \mathrm{k} \cdot \mathrm{mol}^{-1}$. 
Table 3. Thermodynamic parameter for HBCTI-complex formation in different solvents.

\begin{tabular}{|c|c|c|c|c|c|}
\hline Complex & $\begin{array}{c}\text { Temp. } \\
\text { K }\end{array}$ & $\begin{array}{c}K_{C T} \times 10^{-3} \\
\left(\mathrm{~L} \cdot \mathrm{mol}^{-1}\right)\end{array}$ & $\begin{array}{c}-\Delta H^{\circ} \\
\left(\mathrm{k} \cdot \mathrm{J} \cdot \mathrm{mol}^{-1}\right)\end{array}$ & $\begin{array}{c}\Delta S^{\circ} \\
\left(\mathrm{J} \cdot \mathrm{k}^{-1} \cdot \mathrm{mol}^{-1}\right)\end{array}$ & $\begin{array}{c}-\Delta G^{\circ} \\
\left(\mathrm{k} \cdot \mathrm{J} \cdot \mathrm{mol}^{-1}\right)\end{array}$ \\
\hline \multirow{12}{*}{$\begin{array}{c}\text { Complex } \\
\text { (DAT:CLA) }\end{array}$} & $\underline{\text { EtOH }}$ & & \multirow{12}{*}{1.28} & \multirow{7}{*}{64.5} & \multirow{7}{*}{20.5} \\
\hline & 293 & 3.95 & & & \\
\hline & 298 & 3.90 & & & \\
\hline & 303 & 3.89 & & & \\
\hline & 308 & 3.84 & & & \\
\hline & \multicolumn{2}{|l|}{$\underline{\mathrm{MeOH}}$} & & & \\
\hline & 313 & 3.82 & & & \\
\hline & 293 & 3.22 & & \multirow{5}{*}{62.6} & \multirow{5}{*}{20.00} \\
\hline & 298 & 3.20 & & & \\
\hline & 303 & 3.17 & & & \\
\hline & 308 & 3.14 & & & \\
\hline & 313 & 3.11 & & & \\
\hline \multirow{12}{*}{$\begin{array}{c}\text { Complex } \\
\text { (MTDA:CLA) }\end{array}$} & $\underline{\text { EtOH }}$ & & \multirow{7}{*}{4.65} & \multirow{7}{*}{55.9} & \multirow{7}{*}{25.9} \\
\hline & 293 & 5.56 & & & \\
\hline & 298 & 5.44 & & & \\
\hline & 303 & 5.26 & & & \\
\hline & 308 & 5.14 & & & \\
\hline & 313 & 4.91 & & & \\
\hline & $\underline{\mathrm{MeOH}}$ & & & & \\
\hline & 293 & 4.90 & \multirow{5}{*}{3.15} & \multirow{5}{*}{60.0} & \multirow{5}{*}{16.4} \\
\hline & 298 & 4.85 & & & \\
\hline & 303 & 4.73 & & & \\
\hline & 308 & 4.70 & & & \\
\hline & 313 & 4.49 & & & \\
\hline
\end{tabular}

The standard Gibbs free energy change of the complexation process $\left(\Delta G^{\circ}\right)$ was estimated from the $K_{C T}$ value at room temperature using Equation (9). The negative value of $\Delta G^{\circ}$ (Table 3 ) indicates the spontaneous reaction between donors and acceptor with strong interaction as can be understood from the high negative value of $\Delta G^{\circ}$.

$$
\Delta G^{\circ}=\frac{-2.303 \times 8.314 \times 298 \log K_{C T}}{1000}
$$

\subsection{Application of the Studied HBCTI Reaction}

Based on the formation of stable purple colored $C T$-complex between CLA and donors, we proposed in this section a simple, rapid, and accurate spectrophotometric method for determination of donors. Hence, under the optimum reaction conditions Beer's plot at various 1:1 molar ratio between donors and CLA was constructed (Figure 5). The regression equations in both $\mathrm{EtOH}$ and $\mathrm{MeOH}$ were studied by the least square method. 

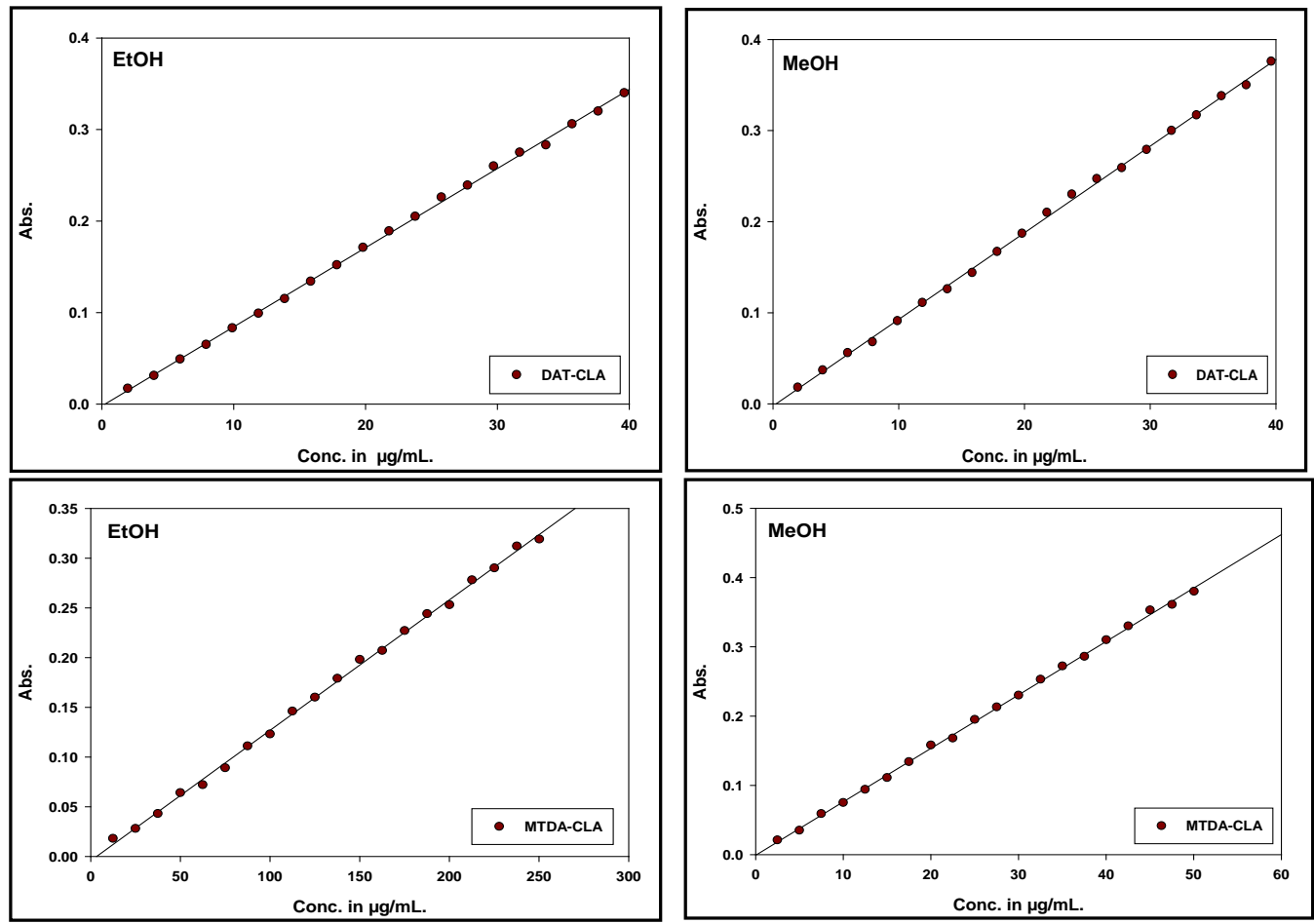

Figure 5. Beer's law plot for HBCTI-complexes in different solvents.

In all cases, Beer's law plots were linear with very small intercepts, slopes and good correlation coefficients in the general concentration ranges $(1.98-39.60$ $\left.\mu \mathrm{g} \cdot \mathrm{mL}^{-1}\right)$ in Complex (DAT:CLA) and $\left(2.50-50.1 \mu \mathrm{g} \cdot \mathrm{mL}^{-1}\right)$ in Complex (MTDA:CLA) (Table 4). The limits of detection and quantification were calculated according to the IUPAC definition [19]. The calculated values were listed in Table 4. They recorded small values confirming the high accuracy of methods studied. It has been found also that the confidence intervals of intercept and slope recorded small values confirming excellent linearity between the absorbance and concentration (Table 4). The accuracy and precision of the method was established by performing analysis of solutions containing five different amounts (within Beer's law limits) of all donors and measuring the absorbance of their HBCT complexes with CLA in EtOH and $\mathrm{MeOH}$. The concentration of donors was determined from the regression equation and then calculated the recovery percentages, the standard deviation $\mathrm{SD}$, and relative standard deviation RSD. The recovery percentages recorder values near $100 \%$ with RSD ranging from 0.7547 to 0.8323 in Complex (DAT:CLA), while the complex (MTDA:CLA) value from 1.49 to 1.94 confirming high accuracy and precision of the proposed method (Table 5). Comparison of the difference between the mean and true value [20] with the largest difference that could be executed as a result of indeterminate error $\frac{ \pm t s}{\sqrt{n}}$ has been carried out and the results were collected in Table 5. It has been found that $(\bar{X}-\mu)$ were less than $\frac{ \pm t s}{\sqrt{n}}$ indicating that no significant difference exists between the mean and true values. 
Table 4. Quantitative parameters of HBCTI-complexes in EtOH and $\mathrm{MeOH}$.

\begin{tabular}{|c|c|c|c|}
\hline Complex & Parameter & Ethanol & Methanol \\
\hline \multirow{7}{*}{$\begin{array}{c}\text { Complex } \\
\text { (DAT:CLA) }\end{array}$} & Beer's law limits, $\mu \mathrm{g} \cdot \mathrm{mL}^{-1}$ & $1.98-39.64$ & $1.98-39.64$ \\
\hline & Limit of detection, $\mu \mathrm{g} \cdot \mathrm{mL}^{-1}$ & 0.9900 & 1.0419 \\
\hline & Limit of quantification, $\mu \mathrm{g} \cdot \mathrm{mL}^{-1}$ & 3.2991 & 3.4728 \\
\hline & Regression equation & $Y=0.008652 X-0.002089$ & $Y=0.009507 X-0.002284$ \\
\hline & Intercept, a & $-0.002089 \pm 0.00132595$ & $-0.002284 \pm 0.001534$ \\
\hline & Slope, b & $0.008652 \pm 0.0000558523$ & $0.009507 \pm 0.00006460$ \\
\hline & Correlation coefficient, $R^{2}$ & 0.99925 & 0.99917 \\
\hline \multirow{7}{*}{$\begin{array}{c}\text { Complex } \\
\text { (MTDA:CLA) }\end{array}$} & Beer's law limits, $\mu \mathrm{g} \cdot \mathrm{mL}^{-1}$ & $2.50-50.1$ & $2.50-50.1$ \\
\hline & Limit of detection, $\mu \mathrm{g} \cdot \mathrm{mL}^{-1}$ & 0.658 & 0.122 \\
\hline & Limit of quantification, $\mu \mathrm{g} \cdot \mathrm{mL}^{-1}$ & 0.685 & 0.147 \\
\hline & Regression equation & $Y=0.006558 X-0.004268$ & $Y=0.007716 X-0.002284$ \\
\hline & Intercept, a & $-0.004268 \pm 0.001767$ & $-0.0008684 \pm 0.001618$ \\
\hline & Slope, b & $0.006558 \pm 0.00005894$ & $0.007716 \pm 0.00005397$ \\
\hline & Correlation coefficient, $\mathbf{R}^{2}$ & 0.998548 & 0.99912 \\
\hline
\end{tabular}

Table 5. Accuracy and precision of the applied spectrophotometric method.

\begin{tabular}{|c|c|c|c|c|c|c|c|c|c|c|}
\hline & Solvent & $\begin{array}{c}\text { Amount } \\
\text { taken } \mu \mathrm{g} \cdot \mathrm{mL}^{-1}\end{array}$ & $\begin{array}{c}\text { Amount found } \\
\mu \mathrm{g} \cdot \mathrm{mL}^{-1}\end{array}$ & $\operatorname{Rec} . \%$ & $\bar{X}$ & SD & RSD & $|\bar{X}-\mu|$ & $\pm \frac{t s}{\sqrt{n}}$ & Confidence limits \\
\hline \multirow{10}{*}{$\begin{array}{c}\text { Complex } \\
\text { (DAT:CLA) }\end{array}$} & \multirow{5}{*}{ Ethanol } & 9.91 & 9.87 & 99.60 & \multirow{5}{*}{100.33} & \multirow{5}{*}{0.7572} & \multirow{5}{*}{0.7547} & \multirow{5}{*}{0.33} & \multirow{5}{*}{ \pm 0.9401} & \multirow{5}{*}{$100.33 \pm 0.9401$} \\
\hline & & 15.85 & 15.80 & 99.68 & & & & & & \\
\hline & & 19.82 & 20.10 & 101.41 & & & & & & \\
\hline & & 27.75 & 28.00 & 100.90 & & & & & & \\
\hline & & 35.67 & 35.70 & 100.08 & & & & & & \\
\hline & \multirow{5}{*}{ Methanol } & 11.90 & 11.90 & 100.00 & \multirow{5}{*}{99.87} & \multirow{5}{*}{0.8312} & \multirow{5}{*}{0.8323} & \multirow{5}{*}{0.13} & \multirow{5}{*}{ \pm 1.0320} & \multirow{5}{*}{$99.87 \pm 1.0320$} \\
\hline & & 17.84 & 17.80 & 99.78 & & & & & & \\
\hline & & 25.76 & 25.62 & 99.46 & & & & & & \\
\hline & & 33.69 & 33.60 & 99.73 & & & & & & \\
\hline & & 39.64 & 39.80 & 100.40 & & & & & & \\
\hline \multirow{10}{*}{$\begin{array}{c}\text { Complex } \\
\text { (MTDA:CLA) }\end{array}$} & \multirow{5}{*}{ Ethanol } & 10.01 & 10.4 & 104.00 & \multirow{5}{*}{101.0} & \multirow{5}{*}{1.956} & \multirow{5}{*}{1.94} & \multirow{5}{*}{0.10} & \multirow{5}{*}{ \pm 2.428} & \multirow{5}{*}{$101.0 \pm 2.428$} \\
\hline & & 17.52 & 17.6 & 100.00 & & & & & & \\
\hline & & 25.03 & 25.0 & 100.00 & & & & & & \\
\hline & & 32.53 & 32.2 & 99.00 & & & & & & \\
\hline & & 45.05 & 44.9 & 99.60 & & & & & & \\
\hline & \multirow{5}{*}{ Methanol } & 7.50 & 7.76 & 103.0 & \multirow{5}{*}{101.0} & \multirow{5}{*}{1.505} & \multirow{5}{*}{1.49} & \multirow{5}{*}{0.10} & \multirow{5}{*}{ \pm 1.868} & \multirow{5}{*}{$101.0 \pm 1.868$} \\
\hline & & 17.52 & 17.50 & 99.8 & & & & & & \\
\hline & & 25.03 & 25.4 & 101.0 & & & & & & \\
\hline & & 30.03 & 29.9 & 99.6 & & & & & & \\
\hline & & 35.04 & 35.4 & 101.0 & & & & & & \\
\hline
\end{tabular}




\section{Conclusion}

A charge and proton transfers complexation reaction of between 3,5-diamino1,2,4-triazole (DAT) and 6-Methyl-1,3,5-triazine-2,4-diamine (MTDA) with 3,6-dichloro-2,5-dihydroxy-p-benzoquinone (chloranilic acid CLA) was studied spectrophotometrically in Ethanol (EtOH) and Methanol $(\mathrm{MeOH})$ solvents at different temperatures have been investigated experimentally by using the spectroscopic techniques UVvis. We got a new band at $\lambda_{\max } 524.5 \mathrm{~nm}$ both in ethanol and methanol in Complex (DAT:CLA), while in complex (MTDA:CLA) there are $524.5 \mathrm{~nm}$ and $524 \mathrm{~nm}$ in ethanol and methanol. The molecular composition of the complex was found to be 1:1 charge transfer complex for both Complex (DAT:CLA) and (MTDA:CLA) by job and spectrophotometric methods. The stability constant was determined in the investigated solvents; they exhibited that MTDA-CLA was higher amounts and the higher stability of the complex (DAT-CLA). The thermodynamic parameters were determined and evaluated; they showed solvent dependency. It is concluded that the formation constant (KCT) of the complexes is found to depend upon the nature of both electron acceptor and donors and on the polarity of solvents.

\section{Conflicts of Interest}

The authors declare no conflicts of interest regarding the publication of this paper.

\section{References}

[1] Kratochvílová, I., Vala, M., Weiter, M., Špérová, M., Schneider, B., Páv, O., Sychrovský, V., et al. (2013) Charge Transfer through DNA/DNA Duplexes and DNA/RNA Hybrids: Complex Theoretical and Experimental Studies. Biophysical Chemistry, 180, 127-134.

https://www.deepdyve.com/lp/elsevier/charge-transfer-through-dna-dna-duplexesand-dna-rna-hybrids-complex-hTrAAJ4pKm https://doi.org/10.1016/j.bpc.2013.07.009

[2] Gaballa, A.S. and Amin, A.S. (2015) Preparation, Spectroscopic and Antibacterial Studies on Charge-Transfer Complexes of 2-Hydroxypyridine with Picric Acid and 7,7’,8,8'-Tetracyano-p-Quinodimethane. Spectrochimica Acta Part A: Molecular and Biomolecular Spectroscopy, 145, 302-312.

https://www.sciencedirect.com/science/article/abs/pii/S1386142515003017 https://doi.org/10.1016/j.saa.2015.03.005

[3] Eldaroti, H.H., Gadir, S.A., Refat, M.S. and Adam, A.M.A. (2014) Charge-Transfer Interaction of Drug Quinidine with Quinol, Picric Acid and DDQ: Spectroscopic Characterization and Biological Activity Studies towards Understanding the Drug-Receptor Mechanism. Journal of Pharmaceutical Analysis, 4, 81-95. https://www.sciencedirect.com/science/article/pii/S2095177913000683 https://doi.org/10.1016/j.jpha.2013.06.003

[4] Al-Ahmary, K.M., El-Kholy, M.M., Al-Solmy, I.A. and Habeeb, M.M. (2013) Spectroscopic Studies and Molecular Orbital Calculations on the Charge Transfer Reaction between DDQ and 2-Aminopyridine. Spectrochimica Acta Part A: Molecular and Biomolecular Spectroscopy, 110, 343-350. 
https://www.sciencedirect.com/science/article/abs/pii/S138614251300276X https://doi.org/10.1016/j.saa.2013.03.055

[5] Bai, H., Wang, Y., Cheng, P., Li, Y., Zhu, D. and Zhan, X. (2014) Acceptor-DonorAcceptor Small Molecules Based on Indacenodithiophene for Efficient Organic Solar Cells. ACS Applied Materials \& Interfaces, 6, 8426-8433.

https://pubs.acs.org/doi/abs/10.1021/am501316y

https://doi.org/10.1021/am501316y

[6] Al-Ahmary, K.M., Habeeb, M.M. and Al-Solmy, E.A. (2011) Spectroscopic Studies of the Hydrogen Bonded Charge Transfer Complex of 2-Aminopyridine with $\pi$-Acceptor Chloranilic Acid in Different Polar Solvents. Journal of Molecular Liquids, 162, 129-134. https://pubs.acs.org/doi/abs/10.1021/am501316y https://doi.org/10.1016/j.molliq.2011.06.015

[7] Chetia, M., Gehlot, P.S., Kumar, A. and Sarma, D. (2018) A Recyclable/Reusable Hydrotalcite Supported Copper Nano Catalyst for 1, 4-Disubstituted-1, 2, 3-Triazole Synthesis via Click Chemistry Approach. Tetrahedron Letters, 59, 397-401. https://www.sciencedirect.com/science/article/pii/S0040403917315575 https://doi.org/10.1016/j.tetlet.2017.12.051

[8] Cascioferro, S., Parrino, B., Spanò, V., Carbone, A., Montalbano, A., Barraja, P., Cirrincione, G., et al. (2017) 1,3,5-Triazines: A Promising Scaffold for Anticancer Drugs Development. European Journal of Medicinal Chemistry, 142, 523-549.

https://www.sciencedirect.com/science/article/pii/S0223523417307493 https://doi.org/10.1016/j.ejmech.2017.09.035

[9] Cascioferro, S., Parrino, B., Spano, V., Carbone, A., Montalbano, A., Barraja, P., Cirrincione, G., et al. (2017) An Overview on the Recent Developments of 1,2,4-Triazine Derivatives as Anticancer Compounds. European Journal of Medicinal Chemistry, 142, 328-375.

https://www.sciencedirect.com/science/article/pii/S0223523417306128 https://doi.org/10.1016/j.ejmech.2017.08.009

[10] Job, P. (1928) Formation and Stability of Inorganic Complexes in Solution. Annali di Chimica Applicata, 9, 133-203.

https://www.scirp.org/(S(351jmbntvnsjtlaadkposzje))/reference/ReferencesPapers.a spx?ReferenceID $=1156687$

[11] Al-Ahmary, K.M. (2014) Spectroscopic Characterization of Charge Transfer Complexes of 2,3-Diaminopyridine with Chloranilic Acid and Dihydroxy-p-Benzoquinone in Polar Solvent. Spectrochimica Acta Part A: Molecular and Biomolecular Spectroscopy, 117, 635-644.

https://www.sciencedirect.com/science/article/abs/pii/S1386142513010159

https://doi.org/10.1016/j.saa.2013.09.008

[12] Voigt, E.M. and Reid, C. (1964) Ionization Potentials of Substituted Benzenes and Their Charge-Transfer Spectra with Tetracyanoethylene. Journal of the American Chemical Society, 86, 3930-3934. https://pubs.acs.org/doi/pdf/10.1021/ja01073a005 https://doi.org/10.1021/ja01073a005

[13] Briegleb, G. (1964) Elektronenaffinitäten organischer Moleküle. Angewandte Chemie, 76, 326-341.

https://onlinelibrary.wiley.com/doi/abs/10.1002/ange.19640760804

[14] Aloisi, G.G. and Pignataro, S. (1973) Molecular Complexes of Substituted Thiophens with $\sigma$ and $\pi$ Acceptors. Charge Transfer Spectra and Ionization Potentials of the Donors. Journal of the Chemical Society, Faraday Transactions 1: Physical Chemistry in Condensed Phases, 69, 534-539.

https://pubs.rsc.org/en/content/articlelanding/1973/f1/f19736900534/unauth\#!divA 
bstract

https://doi.org/10.1039/f19736900534

[15] Briegleb, G. and Czekalla, J. (1960) Intensity of Electron Transition Bands in Electron Donator-Acceptor Complexes. Zeitschrift für physikalische Chemie (Frankfurt), 24, 37-54.

https://www.scirp.org/(S(351jmbntvnsjt1aadkposzje))/reference/ReferencesPapers.a spx?ReferenceID $=419520$

[16] Gliemann, G. (1985) ABP Lever: Inorganic Electronic Spectroscopy, Vol. 33 aus: Studies in Physical and Theoretical Chemistry, Elsevier, Amsterdam, Oxford, New York, Tokio 1984. 863 Seiten, Preis: \$113, 50. Berichte der Bunsengesellschaft für physikalische Chemie, 89, 99-100.

https://onlinelibrary.wiley.com/doi/abs/10.1002/bbpc.19850890122

https://doi.org/10.1002/bbpc.19850890122

[17] Rathore, R., Lindeman, S.V. and Kochi, J.K. (1997) Charge-Transfer Probes for Molecular Recognition via Steric Hindrance in Donor-Acceptor Pairs. Journal of the American Chemical Society, 119, 9393-9404.

https://pubs.acs.org/doi/abs/10.1021/ja9720319 https://doi.org/10.1021/ja9720319

[18] McConnell, H., Ham, J.S. and Platt, J.R. (1953) Regularities in the Spectra of Molecular Complexes. The Journal of Chemical Physics, 21, 66-70.

https://aip.scitation.org/doi/abs/10.1063/1.1698626 https://doi.org/10.1063/1.1698626

[19] Irving, H.M.N.H., Freiser, H. and West, T.S. (2017) Compendium of Analytical Nomenclature: Definitive Rules 1977. Elsevier, Amsterdam. https://books.google.com.sa/books?hl=ar\&lr=\&id=Zmf9BAAAQBAJ\&oi=fnd\&pg= PP1\&dq=Irving, + H. + M. + N. + H., + Freiser,+ H., $+\% 26+$ West,+ T. + S. $+(1981)+$ IUPAC \pm compendium + of + analytical + nomenclature,+ definitive + rules,+ Pergamon + Press,+ $\underline{\mathrm{Ox}}-$ ford.\&ots=K9eMVvJWww\&sig=psoYjzGGEtu1Qswx0edqmbRRo5E\&redir esc=y\#v =onepage \&q\&f=false

[20] Miller, J.C. and Miller, N.A. (2005) Statistics for Analytical Chemistry. 5th Edition, Ellis Horwood Ltd., London.

https://www.amazon.com/Statistics-Chemometrics-Analytical-Chemistry-5th/dp/01 $31291920 / \mathrm{ref}=\mathrm{sr} 1 \mathrm{fkmr} 0 \quad 1$ ? keywords $=.+$ Statistics + for + Analytical + Chemistry\%2C +5 th+ed.+Ellis+Horwood+Ltd.\%2C+England.\&qid=1575104547\&sr=8-1-fkmr0 